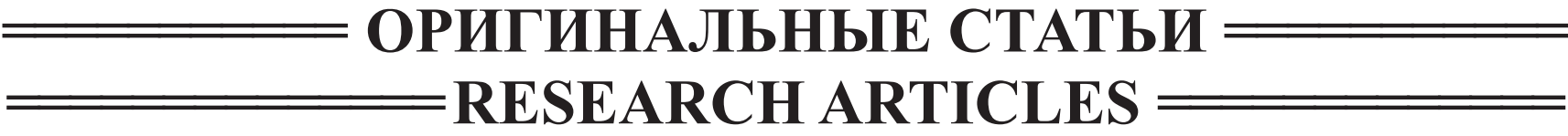 \\ ДОПОЛНЕНИЯ И ИСПРАВЛЕНИЯ К КАДАСТРУ ПРЯМОКРЫЛЫХ НАСЕКОМЫХ (ОRТНОРТЕRА) САМАРСКОЙ ЛУКИ НА ОСНОВАНИИ АНАЛИЗА АКУСТИЧЕСКИХ СИГНАЛОВ САМЦОВ
}

\author{
А. А. Бенедиктов \\ Московский государственный университет имени М.В. Ломоносова, Россия \\ e-mail: entomology@yandex.ru \\ Поступила в редакцию: 05.03.2017
}

\begin{abstract}
Для территории Самарской Луки из поселка Бахилова Поляна (Жигулевский государственный природный биосферный заповедник имени И.И. Спрыгина) и его окрестностей в середине июля 2016 г. было найдено 25 видов Orthoptera на основании анализа акустических сигналов самцов. Это составляет 44\% от всего видового состава Orthoptera Самарской Луки, указанного в Кадастре (2007). Уточнена видовая принадлежность кузнечика Platycleis albopunctata (= P. intermedia auct.), а также впервые указываются сверчок Melanogryllus desertus и саранчовое Chorthippus dorsatus. Обсуждается видовой состав саранчовых криптических таксонов «группы Chorthippus biguttulus» Среднего Поволжья. На основании нестабильной амплитудно-временной структуры сигналов самцов Ch. biguttulus с Малой Бахиловой горы делается предположение, что они могут иметь межвидовое гибридное происхождение.
\end{abstract}

Ключевые слова: Orthoptera, акустические сигналы, Жигули, криптические виды, прямокрылые, Самарская Лука, фаунистика

\section{Введение}

Итог фаунистическим исследованиям прямокрылых насекомых (Orthoptera) национального парка «Самарская Лука» на настоящее время подведен в Кадастре беспозвоночных животных этого региона (Кадастр беспозвоночных животных..., 2007), где указано 57 видов, из них: 16 видов кузнечиковых (Tettigonioidea), 4 вида сверчковых (Grylloidea), 2 вида прыгунчиков (Tetrigoidea) и 35 видов саранчовых (Acridoidea). Однако этот список базируется на работах, выполненных, главным образом, в 1930-1940-е гг. При этом таксономическая часть соответствует представлениям 1950-1960-х гг., поскольку некоторые из видов упоминаются под старыми названиями или в составе других родов. Еще три вида кузнечиков (Poecilimon intermedius (Fieber, 1853), Platycleis affinis Fieber, 1853, Metrioptera brachyptera (Linnaeus, 1761)) указаны из Жигулевска в виде точек на картах Среднего Поволжья (Олигер, 1970), но по каким-то причинам не были включены в кадастр. В то же время за более чем полувековой период были получены новые знания по звукам этих насекомых, что позволяет не только решать сложные таксономические вопросы, но и проводить целенаправленный поиск видов в природе по акустическим сигналам самцов.
В середине июля 2016 г. автор проводил биоакустический мониторинг на территории поселка Бахилова Поляна, где располагается контора Жигулевского государственного природного биосферного заповедника им. И.И. Спрыгина. В результате анализа акустических сигналов насекомых обнаружено, что один из видов кузнечиковых ранее здесь был идентифицирован ошибочно, а два вида (из сверчковых и саранчовых) обнаружены в Самарской Луке впервые. Кроме того, нахождение еще одного вида саранчового, описанного из Тольятти и указанного также из «Жигулей» (Олигер, 1974), требует подтверждения.

\section{Материал и методы}

Наблюдения, биоакустический мониторинг и запись насекомых в природе проводились в поселке Бахилова Поляна с 18 по 23 июля 2016 г., как днем, так и в период сумерек. Были изучены различные биотопы: от старых заброшенных садов с плодовыми деревьями и разнотравных лугов вдоль дороги между конторой и кладбищем, до вершины юго-западной экспозиции Малой Бахиловой горы (со стороны поселка) и пойменных стаций на берегу Волги. Массовый вылов и сбор насекомых в коллекцию не проводился (изымались единичные насекомые, у которых регистрировались акустические сигналы); численность определялась по стридулирующим 
самцам, а также встреченным самкам того или другого вида. Если за 1 час по звуку было отмечено более 20 самцов, то вид считался фоновым, если более 10 - обычным, если более 5 - редким, единичные виды указаны отдельно.

Звуковые сигналы самцов регистрировались при помощи минидиск-рекордера Sony Hi-MD Walkman MZ-RH910 (20-20000 Гц) с микрофоном MIC-01 (40-16000 Гц). Температура при записи +27-30 ${ }^{\circ}$, кроме записи сверчка, сделанной в природе в сумерках, ближе к полуночи при $+18-20^{\circ} \mathrm{C}$. Дальнейшая обработка и анализ осциллограмм проводились на компьютере.

При описании сигналов использована традиционная терминология: сигнал состоит из дискретных серий, каждая серия образована пульсами (Жантиев, 1981), сложный сигнал из серий и пульсов образует фразы.

\section{Результаты и обсуждение}

На территории поселка Бахилова Поляна и в его окрестностях было найдено 25 видов (11 видов кузнечиковых, 2 вида сверчковых, 12 видов саранчовых), что составляет 44\% от всего видового состава Orthoptera Самарской Луки, указанного в Кадастре (2007). Из них 17 видов достоверно подтверждено по звуковым сигналам самцов: Leptophyes albovittata (Kollar, 1833) (обычен здесь на разнотравных лугах, акустические сигналы самцов ультразвуковые); Phaneroptera falcata Poda, 1761 (3 самца, на разнотравных лугах, акустические сигналы большей частью ультразвуковые); Decticus verrucivorus (Linnaeus, 1758) (обычен на разнотравных лугах с низкой растительностью); Metrioptera roeselii (Hagenbach, 1822) (обычен на разнотравных лугах); Pholidoptera griseoaptera (De Geer, 1773) (= Ph. cinerea auct.) (обычен по опушкам); Tettigonia viridissima (Linnaeus, 1758) (обычен в кронах деревьев); T. caudata (Charpentier, 1842) (обычен на высоких кустах и травах); T. cantans (Fuessly, 1775) (1 самец в старом саду); Oеcanthus pellucens (Scopoli, 1763) (фоновый вид, на растениях по опушкам и лугам); Chorthippus apricarius (Linnaeus, 1758) (фоновый вид в нарушенных стациях); Ch. biguttulus (Linnaeus, 1758) (фоновый вид в нарушенных стациях); Ch. macrocerus (Fischer von Waldheim, 1846) (фоновый вид на разнотравных лугах); Ch. parallelus (Zetterstedt, 1821) (обычен по влажным обочинам дорог); Euchorthippus pulvinatus (Fischer von Waldheim, 1846) (обычен на участках с ковылем); Stauroderus scalaris (Fischer von
Waldheim, 1846) (обычен на разнотравных лугах); Chrysochraon dispar (Germar, 1831) (обычен на разнотравных лугах); Euthystira brachyptera (Ocskay, 1826) (обычен на влажных разнотравных лугах). Еще 5 видов обнаружены во время экскурсий без использования биоакустического мониторинга (самки и виды, не издающие громких звуков): Saga pedo (Pallas, 1771) (1 самка, партеногенетический вид, на разнотравных лугах); Metrioptera bicolor (Philippi, 1830) (2 самки, одна из них - forma macroptera, на разнотравных лугах); Calliptamus italicus (Linnaeus, 1758) (обычен на открытых участках лугов, в том числе на юго-западной экспозиции Малой Бахиловой горы); Oedaleus decorus (Germar, 1825) (2 самки, на открытых участках лугов), Oedipoda caerulescens (Linnaeus, 1758) (обычен на открытых участках лугов). Все эти 22 вида присутствуют в Кадастре беспозвоночных животных (2007).

Наконец, три вида: кузнечик Platycleis albopunctata (Goeze, 1778) (в густой растительности по обочинам дорог), сверчок Melanogryllus desertus (Pallas, 1771) (на территории поселка на огородах и открытых участках среди травы, в норках) и саранчовое Chorthippus dorsatus (Zetterstedt, 1821) (обычен на разнотравных лугах), указываются как новые, ранее не отмечавшиеся для данной территории. При этом устанавливается, что в старых работах вид $P$. albopunctata отсюда ошибочно указывался под названием «Platycleis intermedia Serv.». Это заключение подтверждено анализом звуковых сигналов самцов. По каждому из них нужно сказать следующее.

Platycleis albopunctata (Goeze, 1778)

= Platycleis intermedia auct. для юга европейской части России (Корсуновская, 2016).

МАТЕРИАЛ: отмечено более 8 самцов по акустическим сигналам, в зарослях растений вдоль дороги между конторой и кладбищем; записано 2 самца (А.А. Бенедиктов).

ЗАМЕЧАНИЯ. Кузнечики Platycleis albopunctata и P. intermedia (Serville, 1838) являются криптическими видами-двойниками, различить которых по морфологическим признакам не представляется возможным, однако по акустическим сигналам самцов они хорошо идентифицируются (Ragge \& Reynolds, 1998). Ранее считалось, что на территории СССР присутствует P. intermedia, однако по последним данным, включающим биоакустические исследования, 
это заключение ошибочно: его ареал ограничен Западной Европой (Heller et al., 1998; Корсуновская, 2016). Исходя из этого, упоминания о $P$. intermedia с территории, по крайней мере, юга европейской части России (в том числе: Олигер, 1970; Сергеев, 1986; Кадастр беспозвоночных животных..., 2007; Кармазина, Шулаев, 2014), очевидно, следует относить к виду $P$. albopunctata, что также согласовывается с нашими данными. Так анализ осциллограмм звукового сигнала самцов из популяции Жигулевского заповедника (рис. 1: a, b) показывает наличие 4-5 пульсов в серии, что соответствует сигналу P. albopunctata, тогда как у P. intermedia серии 2-пульсовые. Считается (Корсуновская, 2016), что на территории России обитает подвид P. albopunctata transiens Zeuner, 1941.
Melanogryllus desertus (Pallas, 1771)

МАТЕРИАЛ: отмечено по звуку в сумерках около 5 самцов в разных частях поселка, на огородах, в канавах, на нарушенных антропогенной деятельностью участках; акустические сигналы записаны у одного самца (А.А. Бенедиктов).

ЗАМЕЧАНИЯ. ЭТот сверчок хорошо отличается от указанного в Кадастре беспозвоночных животных (2007) Modicogryllus frontalis (Fieber, 1844) полностью черной головой, лишенной светлых поперечных полос между глазами, и немного более крупными размерами. Кроме того, призывный акустический сигнал его самца имеет частотный максимум около 4-5 кГц (у M. frontalis более высокочастотный, 6-8 кГц), а число пульсов в серии почти в 2 раза меньше (в среднем около 7-12) (рис. 1: с, d).

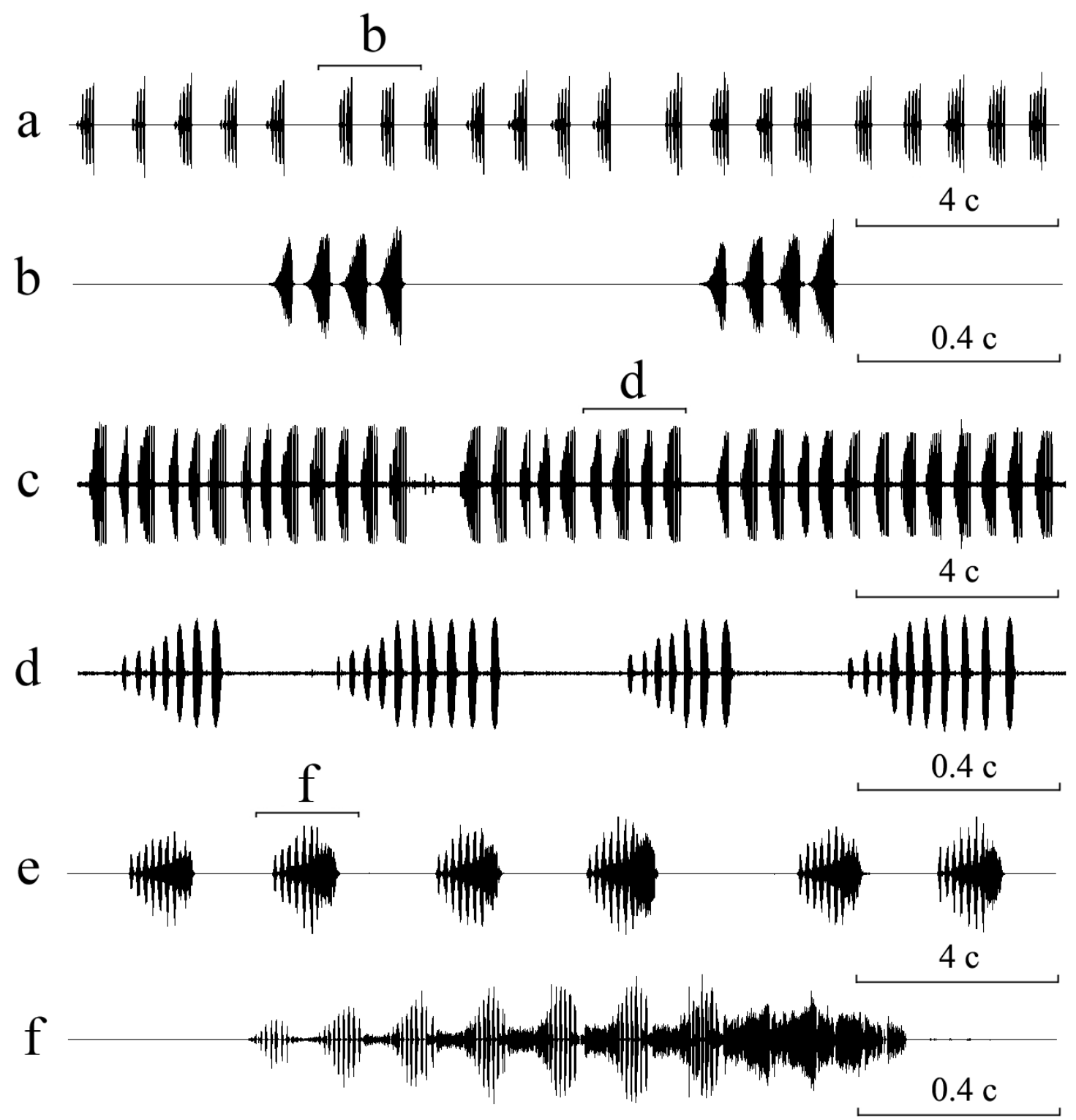

Рис. 1. Осциллограммы призывных сигналов самцов кузнечика Platycleis albopunctata (a, b), сверчка Melanogryllus desertus $(\mathrm{c}, \mathrm{d})$ и саранчового Chorthippus dorsatus $(\mathrm{e}, \mathrm{f})$ на разных скоростях развертки.

Fig. 1. Oscillograms of the calling of the male bush-cricket Platycleis albopunctata (a, b), cricket Melanogryllus desertus (c, d) and grasshopper Chorthippus dorsatus (e, f) at different sweep speed. 
Melanogryllus desertus - степной европейско-казахстанский вид с оптимумом ареала в полупустынной зоне, принадлежит к полупустынному западно-палеарктическому комплексу (Сергеев, 1986). В южных регионах вредит культурным растениям. Скрытный образ жизни и сумеречная активность, вероятно, стали причиной его отсутствия в списке ранее найденных здесь видов. Обнаружение его в Самарской Луке нужно признать вполне закономерным, так как пятью годами ранее он был найден севернее по Волге, в Казани (Кармазина, Шулаев, 2014); указывался также для Самарской области без конкретной точки (Дюжаева, 2004). Здесь проходит северная граница его ареала.

Chorthippus dorsatus (Zetterstedt, 1821)

МАТЕРИАЛ: отмечено более 30 самцов и самок на разнотравных лугах вблизи конторы; акустические сигналы записаны у двух самцов (А.А. Бенедиктов).

ЗАМЕЧАНИЯ. Этот вид также отсутствует в списке Кадастра беспозвоночных животных (2007). На территории Бахиловой Поляны является фоновым на разнотравных лугах. Акустические сигналы самца отличаются от таковых других видов саранчовых Самарской Луки тем, что состоят из двух различных по амплитудновременной модуляции частей (рис. 1: e, f): насекомое меняет алгоритм движения задних ног во время стридуляции и смазывает рисунок в заключительной части каждой фразы сигнала.

Chorthippus dorsatus - северостепной траспалеарктический вид с оптимумом ареала в лесостепной зоне, принадлежит к лесостепному западно-палеарктическому комплексу (Cергеев, 1986). На севере ареала обитает на сухих лугах, хотя проникает и на самый юг Сибири (Тыва) (Бенедиктов, 2005), занимая там более влажные стации, в том числе по берегам водоемов. То, что на территории Самарской Луки до настоящего времени этот вид не отмечался, может быть связано с наличием немногих локальных биотопов, пригодных здесь для его жизни. Замечу, что в более южных районах европейской части России, а также в более ксерофитных лугово-степных стациях его замещает близкий вид Ch. dichrous (Eversmann, 1859), отличающийся по звуковому сигналу самца.

Chorthippus biguttulus (Linnaeus, 1758)

МАТЕРИАЛ: отмечено более 50 самцов и самок на нарушенных антропогенной дея- тельностью участках лугов, а также на юго-западной экспозиции Малой Бахиловой горы от подножия до вершины; акустические сигналы записаны у пяти самцов (А.А. Бенедиктов).

ЗАМЕЧАНИЯ. На территории Среднего Поволжья обитает не менее четырех видов саранчовых «группы Chorthippus biguttulus», или конек изменчивый, а именно: $C h$. biguttulus, Ch. mollis (Charpentier, 1825), Ch. brunneus (Thunberg 1815) и Ch. porphyropterus (см. ниже). Почти все они являются криптическими видами-двойниками, достоверная идентификация которых часто возможна только по звуковым сигналам самцов, при этом их самки практически неразличимы. Дело осложняется тем, что, при совместном обитании некоторые виды этой группы способны образовывать межвидовые природные гибриды с промежуточными признаками, включая характеристики акустических сигналов.

В пределах вида Ch. biguttulus амплитудно-временная модуляция отдельных элементов внутри фразы сигнала носит некоторую изменчивость, хотя сами фразы сохраняют свою форму. Как показали биоакустические исследования, в окрестностях Бахиловой Поляны массово встречается только Ch. biguttulus и особи, близкие по осциллограммам сигналов к этому виду. При этом отмечено небольшое различие сигналов самцов с лугов вблизи конторы (типичный Ch. biguttulus, рис. 2: a, b) и с вершины Малой Бахиловой горы (рис. 2: c-h), у которых отдельные фразы короче, а их внутренняя структура нестабильна, что больше присуще гибридным особям (Gottsberger \& Mayer, 2007; Бенедиктов, 2013). В то же время, ни Ch. mollis, ни Ch. brunneus на слух обнаружены не были, хотя на противоположном берегу Волги (в Тольятти) все три вида обитают синтопично в лесопарковой зоне и подтверждены мною сборами и записями акустических сигналов.

Chorthippus porphyropterus (Vorontsovsky, 1928)

ЗАМЕЧАНИЯ. В 1974 г. по материалу из города Тольятти (также был указан в районе Жигулей по обе стороны реки Волга на песчаных опушках и полянах сосновых лесов без конкретных точек) и Ульяновской области описан Chorthippus brunneus mistshenkoellus (Олигер, 1974), относящийся к саранчовым «группы Ch. biguttulus». Спустя 
25 лет, морфологические исследования типового материала Зоологического института РАН (Санкт-Петербург) показали, что название этого подвида является синонимом $C h$. porphyropterus porphyropterus, описанного из окрестностей Оренбурга (поселок Березовая Ростошь, теперь восточная окраина города) (Бенедиктов, 1999). В связи со сход- ным строением стридуляционного аппарата самца (единственный главный отличительный признак) была установлена синонимия указанных названий (Бенедиктов, 2005). В Кадастре беспозвоночных животных (2007) упоминание об этом таксоне отсутствует. В настоящий момент с территории Самарской Луки мне не известен.
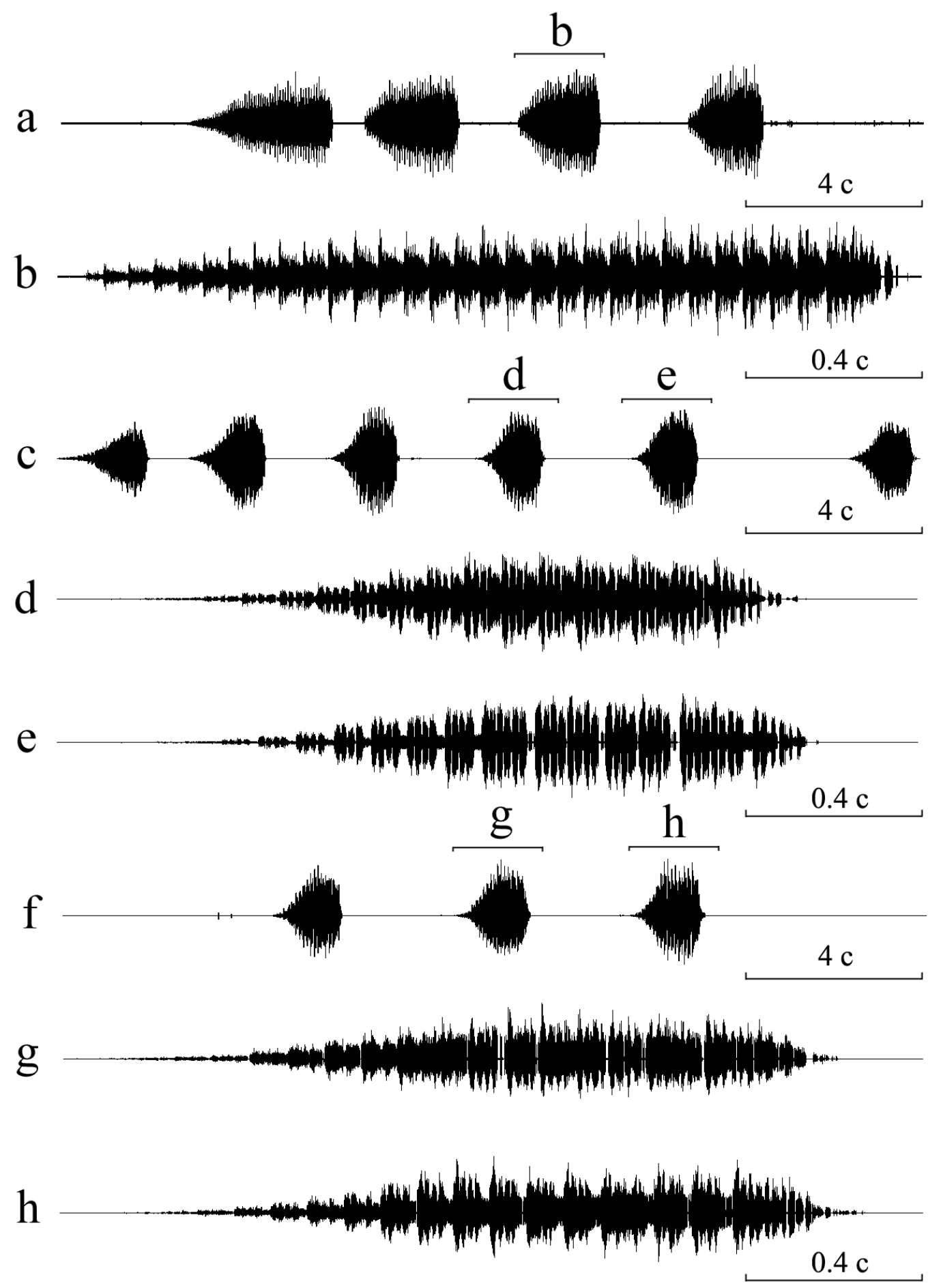

Рис. 2. Осциллограммы призывных сигналов двух самцов саранчового Chorthippus biguttulus с лугов поселка Бахилова Поляна $(\mathrm{a}, \mathrm{b})$ и вершины Малой Бахиловой горы $(\mathrm{c}-\mathrm{h})$ на разных скоростях развертки.

Fig. 2. Oscillograms of the calling of two males of the grasshopper Chorthippus biguttulus from the meadows of the settlement of Bakhilova Polyana $(\mathrm{a}, \mathrm{b})$ and Malaya Bakhilova mountain top $(\mathrm{c}-\mathrm{h})$ at different sweep speed. 


\section{Заключение}

С одной стороны, определение криптических видов-двойников среди прямокрылых насекомых только по морфологическим признакам может привести к серьезным ошибкам независимо от количества выловленных и изученных экземпляров. С другой - использование биоакустического мониторинга и идентификация таксонов дистанционно по звуковым сигналам позволяет в условиях заповедных территорий не наносить существенного вреда флоре и фауне массовым отловом насекомых методом кошения сачком «вслепую» по растениям, а целенаправленно за короткий период времени по звуку находить интересные редкие или новые виды. Наглядным примером тому служит выяснение неверного определения Platycleis albopunctata, а также обнаружение сверчка Melanogryllus desertus и саранчового Chorthippus dorsatus - новых видов для территории Самарской Луки, причем из одной локальной точки Жигулевского государственного природного биосферного заповедника (поселок Бахилова Поляна).

Особого внимания к себе и аккуратного подхода к изучению требует «группа видов Chorthippus biguttulus». Особо отмечу проблему, с которой может столкнуться исследователь, а именно: обнаружение особей и целых популяций с нестабильными характеристиками призывных сигналов, которые с большой долей вероятности можно отнести к межвидовым природным гибридам (обзор в: Бенедиктов, 2013). Этот вопрос требует отдельного изучения.

Подводя итог изучению ортоптерофауны Самарской Луки (Олигер, 1970, 1974; Кадастр беспозвоночных животных..., 2007; новые данные), скажу, что на сегодняшний день общее число указанных отсюда прямокрылых насекомых насчитывает 63 вида, но его еще нельзя признать окончательным. Дело в том, что фауна Orthoptera Волжско-Камского государственного природного биосферного заповедника, расположенного в 210 километрах севернее, по последним данным (Кармазина, Шулаев, 2009) включает всего 40 видов, но ее общность с фауной Самарской Луки составляет только 33 вида - 7 видов здесь не отмечены, но их обнаружение вполне возможно. Кроме того, в списке Кадастра присутствуют таксоны, видовая принадлежность которых не установлена (Poecilimon sp.), а также, по моему мнению, требует дополнительного уточнения (например, некоторые виды рода Stenobothrus spp.). Я уверен, что в фауне «поющих» насекомых этой уникальной заповедной территории в будущем не исключены новые интересные находки.

\section{Благодарности}

Я благодарен директору Жигулевского государственного природного биосферного заповедника им. И.И. Спрыгина Ю.П. Краснобаеву за разрешение проведения работ на территории Бахиловой Поляны, заместителю директора по охране А.Ю. Санарскому, а также научному сотруднику заповедника И.В. Любвиной за помощь в организационных вопросах. Также хочу выразить свою признательность А.П. Михайленко (Москва, Ботанический сад МГУ) за консультации и помощь в подборе литературы. Работа выполнена при поддержке темы НИОКТР (№ AААА-А16-116021660095-7).

\section{Литература}

Бенедиктов А.А. 1999. О малоизвестных таксонах коньков группы Chorthippus biguttulus (Acrididae, Gomphocerinae) // Вестник Московского университета. Сер. 16, биолог. №1. С. 42-45.

Бенедиктов А.А. 2005. Фауна и акустические сигналы саранчовых рода Chorthippus Fieb. (Orthoptera, Acrididae, Gomphocerinae) Южной Сибири // Труды Русского энтомологического общества. Т. 76. С. 118-130.

Бенедиктов А.А. 2013. Находка по акустическому сигналу самца природного гибрида саранчового из группы «Chorthippus biguttulus» (Orthoptera, Acrididae) в Калужской области (Россия) // Эверсманния. №36. С. 8-10.

Дюжаева И.В. 2004. Прямокрылые насекомые (Insecta, Orthoptera) Самарской области // Научные чтения памяти профессора В.В. Станчинского. Вып. 4. Смоленск. С. 114-118.

Жантиев Р.Д. 1981. Биоакустика насекомых. М.: Изд-во Московского университета. 256 с.

Кадастр беспозвоночных животных Самарской Луки: Учебное пособие / под ред. Г.С. Розенберга. Самара: ООО «Офорт», 2007. $471 \mathrm{c.}$

Кармазина И.О., Шулаев Н.В. 2009. Фауна и экология прямокрылых насекомых (Insecta: Orthoptera) Волжско-Камского государственного природного биосферного заповедника // Ученые записки Казанского университета. Серия: Естественные науки. Т. 151(2). С. 173-180.

Кармазина И.О., Шулаев Н.В. 2014. Прямокрылые (Orthoptera) центральной части Волжско-Камского края: рубежи смены фаун и зоогеографическое районирование // Ученые записки Казанского университета. Серия: Естественные науки. Т. 156(2). С. 110-126. 
Корсуновская О.С. 2016. О распространении кузнечика Platycleis albopunctata transiens Zeuner, 1941 (Orthoptera, Tettigoniidae) на юге европейской России и в Узбекистане // Энтомологическое обозрение. Т. 95(2). С. 301-308.

Олигер И.М. 1970. Материалы по фауне прямокрылых надсемейств кузнечиковых и сверчковых (Tettigonioidea et Grylloidea) Среднего Поволжья // Ученые записки Чувашского государственного педагогического института им. И.Я. Яковлева. Серия биологические науки. Вып. 31. С. 108-117.

Олигер И.М. 1974. Таксономическое значение особенностей строения стридуляционного аппарата у видов группы biguttulus рода Chorthippus Fieb. (Orthoptera, Acrididae) // Энтомологическое обозрение. Т. 53(1). С. 81-90.

Сергеев М.Г. 1986. Закономерности распространения прямокрылых насекомых Северной Азии. Новосибирск: Наука. 237 с.

Gottsberger B., Mayer F. 2007. Behavioral sterility of hybrid males in acoustically communicating grasshoppers (Acrididae, Gomphocerinae) // Journal of Comparative Physiology. A. Vol. 193. P. 703-714.

Heller K.-G., Korsunovskaya O.S., Ragge D.R., Vedenina V.Yu., Willemse F., Zhantiev R.D., Frantsevich L.I. 1998. Check-List of European Orthoptera // Articulata. Vol. 7. P. 1-61.

Ragge D.R., Reynolds W.J. 1998. The Songs of the Grasshoppers and Crickets of Western Europe. London: Harley Books, Colchester, Natural History Museum. 591 p.

\section{References}

Benediktov A.A. 1999. To little-known таха of Chorthippus biguttulus group (Orthoptera, Acrididae, Gomphocerinae). Moscow University Biological Sciences Bulletin 1: 42-45. [In Russian]

Benediktov A.A. 2005. Fauna and acoustic signals of the genus Chorthippus Fieb. (Orthoptera, Acrididae) from southern Siberia. Proceedings of the Russian Entomological Society 76: 118-130. [In Russian]

Benediktov A.A. 2013. Acoustical finding of the natural hybrid male grasshopper from «Chorthippus biguttulus - group» (Orthoptera: Acrididae) in Kaluga Province. Eversmannia 36: 8-10. [In Russian]
Dyuzhaeva I.V. 2004. Orthoptera (Insecta) of Samara region. Nauchnye Chteniya Pamyati Professora V.V. Stanchinskogo 4: 114-118. [In Russian]

Gottsberger B., Mayer F. 2007. Behavioral sterility of hybrid males in acoustically communicating grasshoppers (Acrididae, Gomphocerinae). Journal of Comparative Physiology. A 193: 703-714.

Heller K.-G., Korsunovskaya O.S., Ragge D.R., Vedenina V.Yu., Willemse F., Zhantiev R.D., Frantsevich L.I. 1998. Check-List of European Orthoptera. Articulata 7: 1-61.

Karmazina I.O. Shulaev N.V. 2009. Fauna and ecology of Orthoptrous insects (Insecta: Orthoptera) of Volga-Kama State Nature Biosphere Reserve. Proceedings of $\mathrm{Ka}$ zan University. Series: Enviromental Sciences 151(2): 173-180. [In Russian]

Karmazina I.O. Shulaev N.V. 2014. Orthopterous insects (Orthoptera) from the central part of the Volga-Kama region: faunistic barriers and zoogeographical zoning. Proceedings of Kazan University. Series: Enviromental Sciences 156(2): 110-126. [In Russian]

Korsunovskaya O.S. 2016. On the distribution of the bush cricket Platycleis albopunctata transiens Zeuner, 1941 (Orthoptera, Tettigoniidae) in the south of European Russia and in Uzbekistan. Entomological Review. 96(3): 288-293. [In Russian]

Oliger I.M. 1970. Materials on the fauna of orthopterous superfamilies Tettigonioidea and Grylloidea in the Middle Volga region. Proceedings of the I.Ya. Yakovlev Chuvash State Pedagogical University. Series Biological Sciences 31: 108-117. [In Russian]

Oliger I.M. 1974. A taxonomic role of some characters in the structure of the stridulatory apparatus at species of the group biguttulus of the genus Chorthippus Fieb. (orthoptera, Acrididae). Entomological Review 53(1): 81-90. [In Russian]

Ragge D.R., Reynolds W.J. 1998. The Songs of the Grasshoppers and Crickets of Western Europe. London: Harley Books, Colchester, Natural History Museum. 591 p.

Rosenberg G.S. (ed.). 2017. Cadastre of invertebrates of Samarskaya Luka: Tutorial. Samara. 471 p. [In Russian]

Sergeev M.G. 1986. Regularities in distribution of Orthoptera insects of Northern Asia. Novosibirsk: Nauka. 237 p. [In Russian]

Zhantiev R.D. 1981. Bioacoustics of insects. Moscow: Moscow University Press. 256 p. [In Russian] 


\title{
ADDITIONS AND CORRECTIONS TO THE CADASTRE OF ORTHOPTERA INSECTS OF SAMARSKAYA LUKA, ON THE BASIS OF ANALYSIS OF ACOUSTIC SIGNALS OF MALES
}

\author{
Alexander A. Benediktov \\ Lomonosov Moscow State University, Russia \\ e-mail: entomology@yandex.ru
}

For the territory of Samarskaya Luka, at the village Bakhilova Polyana (I.I. Sprygin Zhiguli State Natural Biosphere Reserve), 25 species of Orthoptera were found in mid-July 2016. These species were identified basically by the analysis of male acoustic signals. This is $44 \%$ of the total species composition of Samarskaya Luka Orthoptera, specified in the Cadastre of invertebrates of Samarskaya Luka. The specimens belonging to the grasshopper Platychleis albopunctata (= P. intermedia auct.) are clarified. The cricket Melanogryllus desertus and the locust Chorthippus dorsatus were found for the first time in the Samarskaya Luka. The species composition of the cryptic taxa of the «Chorthippus biguttulus group» of the Middle Volga region is discussed. Based on the unstable amplitude-time structure of the signals of the supposed Ch. biguttulus males from Malaya Bahilova Mountain, it is assumed that they may have a hybrid origin.

Key words: acoustic signals, cryptic species, faunistics, Orthoptera, Samarskaya Luka, Zhiguli 